\title{
ST93-Queensland community-acquired meticillin- resistant Staphylococcus aureus clone in France: outbreak in a scout camp and sporadic cases, July to August 2012
}

TX Nhan (tuxuan.nhan@gmail.com)

J Baverel ${ }^{8}$, B Conscience ${ }^{8}$, J P Lavigne ${ }^{9}$, F Laurent $^{1,3,10}$, J Etienne ${ }^{1,2,3}$, F Vandenesch ${ }^{1,2,3}$, A Tristan ${ }^{1,2,3}$

1. Centre National de Référence des Staphylocoques, Centre de biologie et de pathologie Est, Lyon, France

2. Hospices Civils de Lyon, Centre de biologie et de pathologie Est, Laboratoire de Bactériologie, Bron, France

3. Institut National de la Santé et de la Recherche Médicale (INSERM) U851, Lyon, France

4. Centre Hospitalier Belfort-Montbéliard, Service des Maladies Infectieuses, Belfort, France

5. Centre Hospitalier Belfort-Montbéliard, Laboratoire de Microbiologie, Belfort, France

6. French Institute for Public Health Surveillance (Institut de Veille Sanitaire, InVS), Département des maladies infectieuses, Saint-Maurice, France

7. Agence régionale de santé de Bourgogne, Cellule de l'Institut de Veille Sanitaire en Régions Bourgogne et Franche-Comté, Dijon, France

8. Agence régionale de santé de Franche-Comté, Besançon, France

9. Centre Hospitalier Universitaire de Nîmes, Laboratoire de bactériologie, Nîmes, France

10. Hospices Civils de Lyon, Centre de biologie nord, Laboratoire de Bactériologie, Lyon, France

Citation style for this article:

Nhan TX, Bes M, Meugnier H, Toko L, Julienne G, Thiolet JM, Tillier C, Tessier S, Baverel J, Conscience B, Lavigne JP, Laurent F, Etienne J, Vandenesch F, Tristan A. ST93-Queensland community-acquired meticillin-resistant Staphylococcus aureus clone in France: outbreak in a scout camp and sporadic cases, July to August 2012. Euro Surveill. 2012;17(44):pii=20307. Available online: http://www.eurosurveillance.org/ViewArticle.aspx?Articleld=20307

Article submitted on 12 October 2012 / published on 01 November 2012

We describe the occurrence in France of a PantonValentine leukocidin (PVL)-positive meticillin-resistant Staphylococcus aureus (MRSA) ST93 clone, a predominant community-acquired (CA)-MRSA in Australia. In July to August 2012, an outbreak in a scout camp $(n=3)$ and sporadic cases $(n=2)$ of skin and soft tissue infections were reported. Investigations suggested importation of the clone through travel and onward transmission. This illustrates the epidemic potential of this lineage and the role of travellers in the spread of PVL-positive CA-MRSA.

We describe here the occurrence of sequence type (ST) 93- methicillin-resistant Staphylococcus aureus (MRSA) in France, which led to an outbreak and sporadic cases of skin and soft tissue infections, and the investigation led by public health authorities.

Cases were defined as persons with a skin and soft tissue infection (e.g. furuncle or carbuncle) due to an ST93 S. aureus strain.

\section{Outbreak cases}

The outbreak, comprising three participants of a senior scout camp, occurred in July 2012, in Belfort, in northeastern France. Case 1 (index case), a 25 year-old man, director of the camp, developed furunculosis on the forehead, neck and leg at the beginning of July after being bitten by mosquitoes. He attended the opening of the camp on 11 July and was hospitalised two days later as the lesions had turned into abscesses. He remained in hospital until 17 July. The carbuncles were treated locally and with systemic clindamycin $(600 \mathrm{mg}$ three times a day). He did not return to the camp after his hospital stay.

Case 2, an 18 year-old, developed multiple skin abscesses on his arm three days after his arrival at the camp on 11 July. He was hospitalised from 16 to 19 July and returned to the camp. He was given local treatment for the abscesses, systemic clindamycin (600 mg three times a day).

Case 3, a 16 year-old, who had also arrived at the camp on 11 July, developed two lesions on his arm on 18 July. After consulting his doctor, he was given only local therapy and returned to the camp. A few weeks later, he developed new lesions and he received clindamycin (600 mg three times a day).

All three cases were given information on good hygiene practices.

\section{Sporadic cases}

Two additional cases were also identified elsewhere in France in July and August 2012, in the south and eastcentral parts of the country.

The first, a 20 year-old man had returned to France after a trip to Cambodia (from early June to 18 July). On 8 July, he developed from furunculosis on his legs after a massage. He was treated with amoxicillin-clavulanic 
acid on 13 July. The day after his arrival in France, an abscess on his wrist appeared, with no symptoms of arthritis. Despite treatment, he was admitted to hospital in Nîmes in southern France, for incision and drainage of the abscess. Following culture analysis (see below), he received clindamycin plus rifampicin and slowly recovered well, but furunculosis then reappeared three months later.

The second sporadic case, a seven year-old boy, attended the emergency department of a hospital in Lyon on 28 August with a fistulised skin abscess on the elbow and a history of recurrent boils. Three weeks previously, he had received local therapy for a furuncle. No epidemiological data (such as recent travel, information on any other cases among his close contacts) could be collected because the child was lost to follow-up.

\section{Laboratory analysis}

Culture from the furuncles or carbuncles from all five patients yielded $S$. aureus isolates, which were sent to the French reference centre for staphylococci in Lyon. Antimicrobial susceptibility testing (penicillin, oxacillin, kanamycin, tobramycin, gentamicin, erythromycin, lincomycin, pristinamycin, levofloxacin, fusidic acid, fosfomycin, tetracycline, rifampicin, trimethoprimsulfamethoxazole, chloramphenicol and linezolid) was performed by disk diffusion assay and interpreted according to the 2012 guidelines of the Antibiogram Committee of the French Society for Microbiology [1]. All the isolates were only resistant to meticillin.

Molecular characterisation of all the strains was conducted by agr typing (by PCR) [2], SCCmec typing and toxin profiling (using DNA microarrays) [3,4] and the assignment of isolates to ST (by multilocus sequence typing (MLST)) $[5,6]$. They harboured the agr 3 allele and Panton-Valentine leukocidin (PVL) genes and belonged to the same clone, namely ST93-SCCmecIV.

\section{Epidemiological investigations of the outbreak cases}

We defined an outbreak as the occurrence of at least three cases with the indistinguishable $S$. aureus strain in a specific population. This took into account the genotypic profile of the strain. The incubation period for $S$. aureus is variable and undefined, thus the time from infection to symptom onset is not a criterion for identification of an outbreak. However, the occurrence of the cases within a month could be a criterion to support the identification of outbreak [7].

Investigations carried out by public health authorities found that Case 1 had travelled to Papua New Guinea from May to late June 2012. He was not aware of having been in contact with anyone with furunculosis or skin abscesses. On his return journey to France, he stopped in Singapore and the first episode of furunculosis appeared a few days later.
It was established that there had been skin-to-skin contact between Cases 1 and 2 during a sports activity at the camp, suggesting direct bacterial transmission.

Cases 2 and 3 shared the same tent, which allows transmission of the causative agent via direct contact or possible sharing of personal items (e.g. clothes, linen and towels).

\section{Control measures at the scout camp}

Control measures were implemented, which included disinfection with hydroalcoholic solution of the hands of the three cases at the camp. Those attending the camp were advised orally by the public health authorities not to share personal items and the three cases slept in individual tents. The outbreak was contained within the camp: it closed on 27 July.

\section{Background}

In recent years, PVL-positive MRSA has become an important cause of community-acquired skin and soft tissue infections [8]. Some epidemic clones have spread worldwide and have a specific geographical distribution: in France, the European ST80 clone is dominant while in Australia, ST93 (also known as the Queensland clone) is the most common $[9,10]$.

\section{Discussion}

This is the first observation of ST93-MRSA grouped infections in France and it highlights the epidemic potential of this lineage. Since its first description in 2003, ST93-MRSA has spread extensively in the community and in hospitals in Australia, where it is the predominant CA-MRSA $[10,11]$, accounting for about $64 \%$ of all CA-MRSA infections [12]. International spread of the ST93 clone was reported in United Kingdom in 2010, comprising a small number of epidemiologically linked cases in connection with travel to Australia [13].

Similarly, the French epidemiological investigations suggested that importation of the ST93 strain as a result of foreign travel and clonal dissemination of this lineage has occurred in France. This underlines the potential role of travellers in the intercontinental spread of strains, as observed for other CA-MRSA strains, such as the USA300 strain in France in 2009 [14].

The demography, clinical presentation and transmissibility among the patients at the scout camp were in agreement with data from Australia and CA-MRSA in general [12]. Moreover, factors facilitating the spread of infection were found, including crowding, skin-toskin contact between individuals and possible sharing of contaminated personal items.

This report also highlights the importance of enhanced hygiene measures and appropriate treatment to control the spread of the infection. The outbreak in the scout camp was contained using good hygiene practices, as recommended by French guidelines for the 
management of CA-MRSA infections [7], without screening the exposed population for carriage or systematic decolonisation.

Despite the small number of ST93-infections reported here, their occurrence in a short period of time and their occurrence in various parts of France are of concern. Enhanced surveillance is therefore necessary to determine whether this lineage will spread further in France.

\section{References}

1. French Society of Microbiology (SFM). Comité de l'antibiogramme de la société française de microbiologie - recommandations 2012. [Guidelines of the Antimicrobial Committee of the French Society of Microbiology]. Paris : SFM; 2012. French. Available from: http://www.sfm-microbiologie. org $/$ pages $/$ ? page $=746 \&$ id_page $=180$

2. Jarraud S, Mougel C, Thioulouse J, Lina G, Meugnier H, Forey F, et al. Relationships between Staphylococcus aureus genetic background, virulence factors, agr groups (alleles), and human disease. Infect Immun. 2002;70(2):631-41.

3. Monecke S, Jatzwauk L, Weber S, Slickers P, Ehricht R. DNA microarray-based genotyping of methicillin-resistant Staphylococcus aureus strains from Eastern Saxony. Clin Microbiol Infect. 2008;14(6):534-45.

4. Monecke S, Slickers P, Ehricht R. Assignment of Staphylococcus aureus isolates to clonal complexes based on microarray analysis and pattern recognition. FEMS Immunol Med Microbiol. 2008;53(2):237-51.

5. MLST. Multi locus sequence typing. [Accessed 22 Dec 2012]. Available from: http://saureus.mlst.net/

6. Enright MC, Day NP, Davies CE, Peacock SJ, Spratt BG. Multilocus sequence typing for characterization of methicillinresistant and methicillin-susceptible clones of Staphylococcus aureus. J Clin Microbiol. 2000;38(3):1008-15.

7. High Council of Public Health (HCSP). Recommandations sur la prise en charge et la prévention des infections cutanées liées aux souches de Staphylococcus aureus résistants à la méticilline communautaires (SARM CO). [Recommendations on the management and prevention of skin infections related to CA-MRSA]. Paris: HCSP; 2009. French. Available from: http://www.hcsp.fr/docspdf/avisrapports/hcspr20091020 previnfcutsarm.pdf

8. Vandenesch F, Naimi T, Enright MC, Lina G, Nimmo GR, Heffernan $\mathrm{H}$, et al. Community-acquired methicillinresistant Staphylococcus aureus carrying Panton-Valentine leukocidin genes: worldwide emergence. Emerg Infect Dis. 2003;9(8):978-84.

9. Tristan A, Bes M, Meugnier H, Lina G, Bozdogan B, Courvalin $P$, et al. Global distribution of Panton-Valentine leukocidin-positive methicillin-resistant Staphylococcus aureus, 2006. Emerg Infect Dis. 2007;13(4):594-600.

10. Coombs GW, Nimmo GR, Pearson JC, Christiansen KJ, Bell $J M$, Collignon PJ, et al. Prevalence of MRSA strains among Staphylococcus aureus isolated from outpatients, 2006. Commun Dis Intell. 2009;33(1):10-20.

11. Munckhof WJ, Schooneveldt J, Coombs GW, Hoare J, Nimmo GR. Emergence of community-acquired methicillin-resistant Staphylococcus aureus (MRSA) infection in Queensland, Australia. Int J Infect Dis. 2003;7(4):259-64.

12. Nimmo GR, Schooneveldt JM, Sutherland JL, Power S, Olesen D, Selvey C, et al. Epidemiology of non-multiresistant methicillinresistant Staphylococcus aureus infection in Queensland, Australia: associations with indigenous populations and Panton-Valentine leukocidin. Eur J Clin Microbiol Infect Dis. 2010;29(10):1253-9.

13. Ellington MJ, Ganner M, Warner M, Boakes E, Cookson BD, Hill RL, et al. First international spread and dissemination of the virulent Queensland community-associated methicillinresistant Staphylococcus aureus strain. Clin Microbiol Infect. 2010;16(7):1009-12.

14. Del Giudice P, Blanc-Amrane V, Bes M, Lina G, Hubiche T, Counillon $E$, et al. [A case of indigenous skin infection caused by methicillin-resistant Staphylococcus aureus USA300 in France]. Ann Dermatol Venereol. 2009;136(6-7):541-2. French 